\title{
Sound production during competitive feeding in the grey gurnard
}

\author{
M. C. P. Amorim*†, Y. Stratoudakis \\ AND A. D. HAWKINS* \\ *FRS Marine Laboratory, P. O. Box 101, Victoria Road, Aberdeen, AB11 9DB, U.K., \\ $\ddagger$ Instituto de Investigação das Pescas e do Mar (IPIMAR), 1449-006 Lisboa, \\ Portugal and §Department of Land Economy, University of Aberdeen, St Mary's \\ King's College, Aberdeen, AB $243 U F$, U.K.
}

(Received 9 January 2004, Accepted 6 April 2004)

\begin{abstract}
The acoustic repertoire of captive grey gurnard Eutrigla gurnardus during competitive feeding consisted of three types of sound: knocks, grunts and growls. Knocks were audible as a single sound, whereas grunts and growls were perceived as longer, pulsed sounds to the human ear. Typically, knocks were composed of 1-2 pulses, grunts of 4-8 pulses and growls $>10$ pulses. Growls were longer and had shorter pulse periods than grunts. All sound types had peak frequencies of $c .500 \mathrm{~Hz}$. The sequences of behaviours observed during feeding interactions suggest that grey gurnard obtain food both by scramble and contest tactics. Competing fish emitted knocks mainly while grasping a food item and also during other non-agonistic behaviour, suggesting that knock production may reflect a state of feeding arousal but could also serve as a warning of the forager's presence to nearby competitors. Grunts were mainly emitted during frontal displays, which were the most frequent behavioural act preceding grasps, suggesting that they may play a role in deterring other fish from gaining access to disputed food items.

(C) 2004 The Fisheries Society of the British Isles
\end{abstract}

Key words: agonistic behaviour; bioacoustics; calling; scramble and contest competition; teleosts.

\section{INTRODUCTION}

Fish produce sounds that are usually made up of short repeated low frequency pulses with a large variation in their temporal characteristics (Hawkins, 1993; Ladich, 2003). Sound production during agonistic behaviour is widespread in fishes (Ladich, 1997) and may give an advantage in territory defense (Rigley \& Muir, 1979; Myrberg, 1997), the outcome of contests (Valinski \& Rigley, 1981; Ladich et al., 1992) and in regulating the opponent's aggressive behaviour (Schwarz, 1974; Rigley \& Muir, 1979). Most accounts of acoustic emissions by fishes in agonistic contexts are related to territorial defense, often associated with reproduction (Hawkins, 1993; Ladich, 1997). Few are associated with competitive aggression at smaller temporal and spatial scales, as, for example, during brief contests over ephemeral resources such as food patches.

$\uparrow$ Author to whom correspondence should be addressed at present address: Unidade de Investigação em Eco-Etologia, ISPA, Rua Jardim do Tabaco 34, 1149-041 Lisboa, Portugal. Tel.: +351 218811700; fax: +351 218860954; email: amorim@ispa.pt 
Competition for limited food resources may be resolved by scramble or contest tactics (Milinsky \& Parker, 1991). When food resources are too costly to monopolize and defend from other competitors, it becomes more advantageous for an individual to simply be faster and more efficient than others in acquiring food without dispute (scramble competition; Grant, 1993). As resources become more clumped in space, less clumped in time and more predictable in both space and time, they become more economically defensible, and hence an animal's aggressiveness is predicted to increase (contest competition; Grant, 1993; Robb \& Grant, 1998; Goldberg et al., 2001). Animals often resolve such contests with displays, during which acoustic communication can co-occur with visual or other types of signals (Huntingford \& Turner, 1987).

Sound production is widespread amongst species of the family Triglidae and the sound producing ability of these fishes was already known to fishermen in Aristotle's time (Moulton, 1963). Sound production and associated behaviour, however, has been poorly studied in this family (Amorim \& Hawkins, 2000), perhaps because field work is greatly limited by the depths at which triglids live (Wheeler, 1969; Papaconstantinou, 1983). The grey gurnard Eutrigla gurnardus (L.), is a common benthic gregarious species in coastal waters of the eastern North Atlantic, typically found at depths down to $140 \mathrm{~m}$ (Wheeler, 1969), in small (Protasov, 1965) to occasionally extremely large shoals (H.J.L. Heesen \& N. Daan, pers. comm.). This species has a pair of strongly developed intrinsic sonic muscles embedded laterally on each side of the swim bladder wall and produces typical swim bladder sounds composed of brief low frequency pulses repeated at different rates, which are easily heard under laboratory conditions during staged feeding (Amorim, 1996). In this study, the sounds produced by captive grey gurnards during competitive feeding interactions were investigated. The sequences of behaviour occurring during feeding interactions were studied to identify the types of strategies used during competitive feeding. Finally, the association of emissions of different sound types with accompanying behaviour was determined.

\section{MATERIALS AND METHODS}

\section{FISH COLLECTION AND MAINTENANCE}

Fish were trawled at depths of $15-40 \mathrm{~m}$ in the North Sea and taken to the aquarium facilities of the FRS Marine Laboratory, Aberdeen (U.K.). Subject fish were kept indoors under a computer-controlled day-night schedule, set to simulate the natural photoperiod $\left(57^{\circ} 08^{\prime} \mathrm{N}\right)$. Experimental tanks were provided with treated re-circulated sea water (filtered and sterilized), with temperatures ranging from $7^{\circ} \mathrm{C}$ (winter) to $12^{\circ} \mathrm{C}$ (summer). For experiments, fish were kept in four groups of four to eight individuals of similar size. Smaller specimens $\left(10-20 \mathrm{~cm}\right.$ total length, $\left.L_{\mathrm{T}}\right)$ were kept in 1.5 and $3 \mathrm{~m}$ diameter fibreglass tanks, and larger specimens $\left(25-40 \mathrm{~cm} L_{\mathrm{T}}\right)$ in a swimming-pool of $7 \cdot 0 \times 3.5 \times 1.5 \mathrm{~m}$, length $\times$ width $\times$ depth, with a sand bottom. Fish were fed three times a week, with dead fishes or shrimp. Fish were of both sexes, but were sexually inactive.

\section{ACOUSTIC REPERTOIRE}

Sounds were recorded from the four fish groups during $5 \mathrm{~min}$ feeding sessions two to three times a week, throughout 1 year. The sound recording equipment consisted of a 
hydrophone (Plessey, MS83), with a sensitivity of $-170 \mathrm{~dB}$ re $1 \mathrm{~V}$ for $1 \mu \mathrm{Pa}$ and with a flat frequency response from 10 to $40 \mathrm{kHz}$, a low-noise amplifier (Brookdeal, model 450) and a DAT recorder (Casio, model DA-1). Sounds were analysed using a Loughborough Sound Images Workstation (version 2.0; 1986 Metagraphics Software Corporation ${ }^{\odot}$ ).

Grey gurnard sounds were classified aurally into three types: knocks, grunts and growls. All consisted of repeated low frequency pulses when viewed as oscillograms of sound pressure against time. Knocks were audible to the human ear as a single pulse of sound, whereas grunts and growls were heard as longer pulsed sounds. The following features of sounds were measured: sound duration (time elapsed from the start of the first to the end of the last pulse in a sound, ms); pulse duration (time elapsed between the start and the end of a pulse, averaged for all or at least 10 pulses in long sounds, ms); number of pulses (total number of pulses in a sound); pulse period (mean time elapsed between the peak amplitude of two consecutive pulses, ms); peak frequency (the frequency component with the highest energy in the entire sound, measured for each pulse of sound, Hz). Sounds (knocks, grunts and growls) were emitted alone or in sequences of two to several sounds, here referred as bursts of sounds. The following acoustic features were measured for bursts of sounds: burst duration (time elapsed between the start of the first sound and the end of the last sound within a burst, s); number of sounds (total number of sounds in a burst); interval between sounds (time elapsed between the end and the start of different sounds, ms).

A linear discriminant analysis based on all sound features (Statistica 6.0) was used to validate the adequacy of the aural classification of the three sound types.

\section{BEHAVIOUR}

\section{Video recordings}

Feeding interactions and the association of sound production with behaviour were studied in three of the experimental fish groups by means of video recording and analysis. Video recordings were taken with a Sony video 8 camcorder (CCD-FX500E Pal 8) placed above the tanks and connected to the sound recording system so that the images could be synchronized with the sounds. Ten sessions of video recording lasting $c .15 \mathrm{~min}$ each were obtained for each fish group. Fish were recorded three times a week. Food was dropped every minute through a feeding tube throughout the filming session (from minute 0 to minute 14). Feeding was considered competitive since the food was scarce and it did not exceed demand (Milinsky \& Parker, 1991). The system of feeding chosen was intended to promote maximum competition for food, since food items were clumped in space and were spatially and temporally predictable (Grant, 1993; Goldberg et al., 2001).

\section{Feeding interactions}

Fish were considered to participate in a feeding interaction when they were in close proximity and altered the conspecifics' behaviour. Feeding interactions were characterized by registering the succession of behavioural acts for each fish participating in the interaction. The following behavioural categories were considered: (1) dash, swimming rapidly towards a food item and suddenly stopping just before reaching it and without attempting to grasp it, typically with conspecifics in close vicinity; (2) circle, circling the feeding area without attempting to grasp any food item; (3) grasp, taking a food item into the mouth; (4) orient, turning the head towards a conspecific; (5) approach, slowly swimming or moving on the substratum towards a conspecific, decreasing the distance between the performer and the recipient; (6) chase, similar to approach but in a fast motion; (7) frontal display, spreading out the paired and dorsal fins with the head directed towards the opponent's head; (8) flee, swimming rapidly away from a conspecific.

These behavioural categories were established during preliminary observations carried out during the study of the species' acoustic repertoire. The typical sequences of behavioural acts during feeding interactions were examined by determining which sequences of behaviours were more frequently observed than if they had occurred at random, using a first-order Markov chain analysis that tests for dependence of one act on the previous 
one. A simulation analysis for tests of independence of contingency tables that follows the rationale of a $\chi^{2}$ (programme ACTUS; Estabrook \& Estabrook, 1989) was used to test the dependence of one behavioural act on the previous one (Amorim \& Hawkins, 2000).

\section{Association of sound production with behaviour}

As grey gurnards do not perform specific body movements when emitting sounds and compete for food very actively (several fish can be seen together, all moving and displaying very quickly), it was very difficult to attribute sound production to an individual fish. Hence, the association of sound production with behaviour was studied at the group level. The association of behaviour and sound production was analysed with a one-zero sampling (time sampling) recording technique (Martin \& Bateson, 1993): each video session was divided into $5 \mathrm{~s}$ intervals, and at the end of each sample interval it was noted whether each behavioural category had occurred. The number of grunt and knock bursts emitted were also noted per $5 \mathrm{~s}$ interval. The duration of the sample interval, $5 \mathrm{~s}$, was chosen to optimize the accuracy of the time-sample record and to compromise as little as possible the reliability of recording several categories of behaviour at once (Martin \& Bateson, 1993). Data were pooled at the minute level for analysis by summing the number of $5 \mathrm{~s}$ intervals in which a behavioural category occurred. The number of knock and grunt bursts scored at the $5 \mathrm{~s}$ level were also pooled for each min.

Generalized linear models (GLM, McCulough \& Nelder, 1989) were used to associate the number of knock and grunt bursts produced per minute to the number of grasps, agonistic (orient, approach and chase, frontal display and flee) and non-agonistic (circle and dash) behaviours. The number of sound bursts (grunts or knocks) produced per minute of recording was assumed to follow a Poisson distribution and its expected value was linked to the explanatory variables (time within recording session and number of $5 \mathrm{~s}$ intervals at which each of the three behavioural classes occurred per minute) by a logarithmic link function. GLM were fitted using the open source software R (Venables \& Ripley, 2002) and the resulting models were checked using standard residual inspection plots. The significance of each explanatory variable was tested using $t$-tests which were based on an estimate of the variance obtained by the use of the quasi-Poisson family distribution.

\section{RESULTS}

\section{THE SOUND REPERTOIRE}

Grey gurnards emitted three sound types during competitive feeding: knocks, grunts and growls (Figs 1-3). A discriminant analysis based on the measured acoustic features supported the adequacy of this classification $(n=1080$, Wilks' $\lambda=0 \cdot 139, P<0 \cdot 001)$. Single-pulse knocks were not considered in this analysis since these do not have values for the variable pulse period. More than $90 \%$ of the knocks and grunts, and $73 \%$ of the growls were correctly classified (Table I). The variables that mainly contributed to the discriminant functions were the pulse duration, the number of pulses and the pulse period (Table II).

Pulse duration was shorter in growls than in knocks or grunts, probably due to a shorter pulse period (Table III). Sound duration and number of pulses increased from knock to grunt to growl. Most knocks had one or two pulses (85\%), typical grunts had four to eight pulses (87\%) and typical growls 10 to 40 pulses $(59 \%)$. The peak frequency of all sound types was $c .500 \mathrm{~Hz}$ (Table III). Knock and grunt bursts typically lasted for a little over a second and usually consisted of five consecutive sounds (Table III). Knocks were the most frequent 

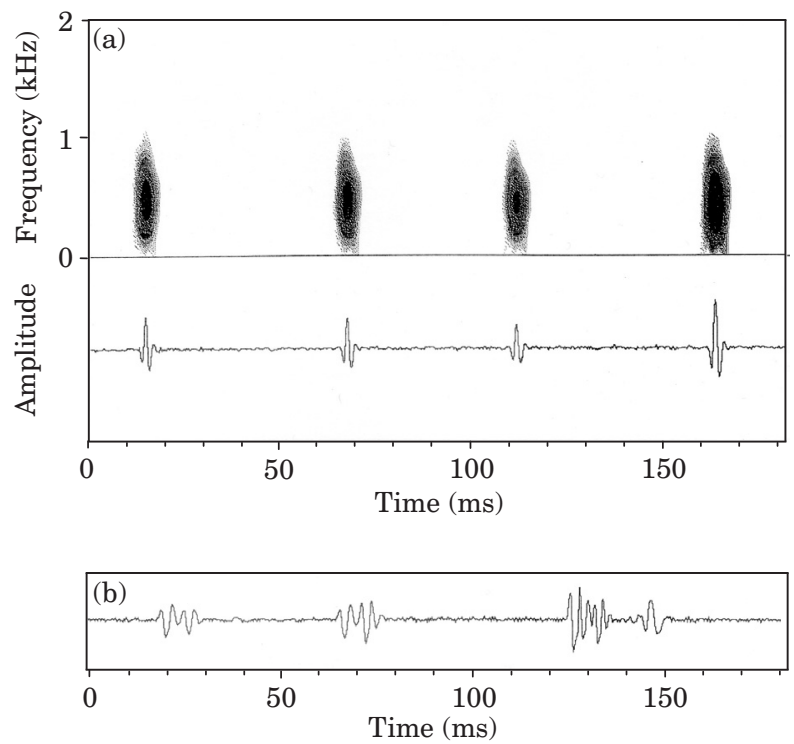

Fig. 1. (a) Sonogram and oscillogram of a burst of single pulsed knocks. (b) A burst of knocks made up of two and three pulses. The filter bandwidth of the sonogram is $125 \mathrm{~Hz}$.

sound type [mean \pm s.D. (range): $9 \cdot 8 \pm 8.6(0-32 \cdot 8)$ knocks $\min ^{-1}$ ] during the 5 min feeding bouts $(n=64)$. Growls occurred rarely $[0.3 \pm 0.7(0-3 \cdot 8)$ growls $\left.\min ^{-1}\right]$, usually within or at the end of grunt bursts $[4 \cdot 6 \pm 4 \cdot 6(0-21 \cdot 6)$ grunts $\left.\min ^{-1}\right]$. Only 64 growls were recorded during this study.

\section{BEHAVIOUR}

Outside feeding periods fish usually stayed on the bottom of the tank, resting or moving with the help of the pectoral fin rays in a small lose shoal, interacting and emitting sounds infrequently (Amorim, 1996). When food was presented, however, most fish swam rapidly towards the feeding area and attempted to

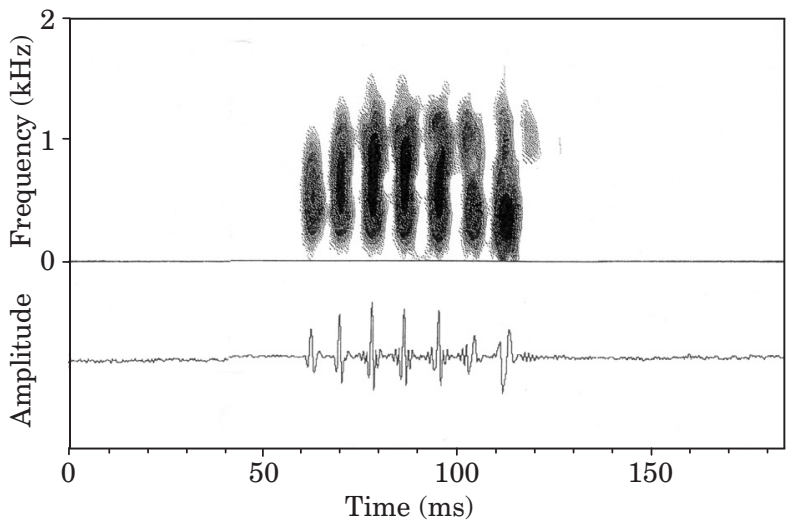

FIG. 2. Sonogram and oscillogram of a grunt with seven pulses (filter bandwidth of $125 \mathrm{~Hz}$ ). 

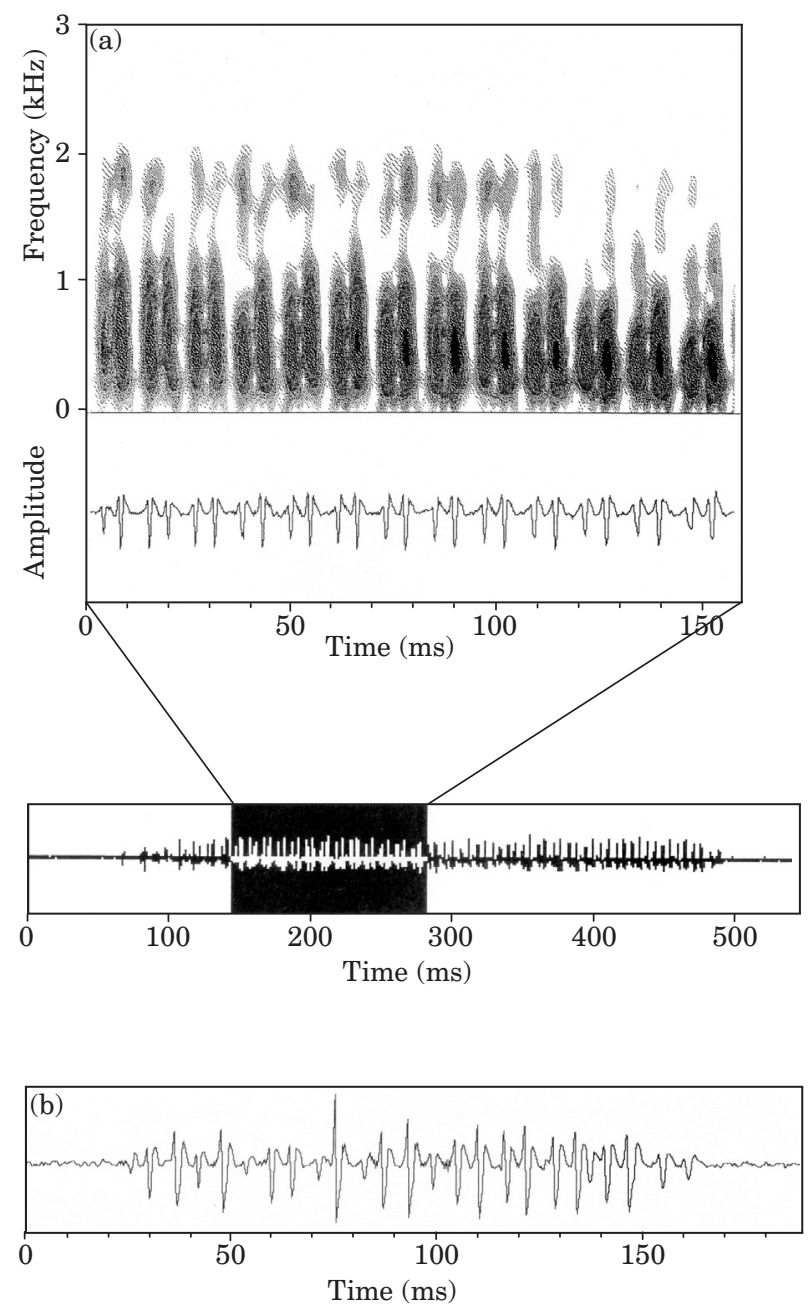

FIG. 3. (a) Sonogram and oscillogram of a section of a growl and the envelope of the complete growl showing its 78 pulses. The filter bandwidth of the sonogram is $125 \mathrm{~Hz}$. Note pulses occur in pairs. (b) Oscillogram of a shorter growl with 24 pulses in which a double-pulse structure is not clear.

grasp the food, resulting in a marked increase in the frequency of social interactions and sound production. Grasp was the behaviour that most frequently started a sequence of behaviour in an interaction $(n=698,38 \cdot 5 \%)$, followed by dash $(29.8 \%)$ and approach (19.2\%). Interactions typically involved two to three fish $[2.67 \pm 0.74(2-5)]$. It was rare $(15.3 \%)$, however, that more than one of the interacting fish started an interaction by grasping food and in $26 \cdot 1 \%$ of the cases none of the interacting fish initiated a behavioural sequence with a grasp. This suggests that when food is presented, fish rush to the feeding area with only one usually immediately grasping a piece of food and deterring competitors from grasping simultaneously. The other fish dash or approach the successful conspecific. Interacting fish then start a sequence of behaviours (Fig. 4) that eventually leads to one or more grasps by all interacting individuals. 
TABLE I. Summary of sound type classification given by linear discriminant analysis. Columns show the reallocation of sounds in each group (sound type). Knocks with only one pulse were not used in the analysis

\begin{tabular}{lccc}
\hline & \multicolumn{3}{c}{ True group } \\
\hline Sound type & Knock & Grunt & Growl \\
Knock & 297 & 41 & 10 \\
Grunt & 28 & 649 & 7 \\
Growl & 0 & 1 & 47 \\
Total $n^{1}$ & 325 & 691 & 64 \\
Proportion correct $(\%)$ & $91 \cdot 4$ & 93.9 & 73.4 \\
\hline
\end{tabular}

${ }^{1}$ Total number of each sound type analysed.

The sequences of behavioural acts observed during feeding interactions that occurred more frequently than expected by chance are depicted in Fig. 4. Typically food was either obtained directly by grasping or by waiting for an opportunity to grasp (circle and grasp), or by means of aggressive behaviour. The behavioural act that most frequently preceded grasp was frontal display $(40 \cdot 5 \%$; any other act had values $<17 \%)$ suggesting that the frontal display was an effective means of gaining access to food. Fleeing mostly ended feeding interactions for the fish concerned.

Bursts of knocks were significantly associated with grasps and also with nonagonistic behaviour (dash and circle; Fig. 5 and Table IV), while the relation with agonistic behaviour was non-significant. On the contrary, bursts of grunts were mostly associated with agonistic behaviour (Fig. 5 and Table IV), while there was a marginally significant relation with grasp and a non-significant relation with non-agonistic behaviour. Repeating the analysis on grunts separately for each type of agonistic behaviour showed that the most significant relation was obtained for the behaviour frontal display. Both knock and grunt emissions decreased with time (Fig. 5).

\section{DISCUSSION}

The grey gurnard produced three types of sound during competitive feeding (knocks, grunts and growls), which were associated with different behavioural

TABLE II. Linear discriminant functions for the validation of sound type classification

\begin{tabular}{lrrr}
\hline & \multicolumn{3}{c}{ Discriminant functions } \\
\hline Variables & 1 & 2 & \multicolumn{1}{c}{3} \\
Constant & -48.51 & $-48 \cdot 46$ & $-55 \cdot 58$ \\
Number of pulses & 0.93 & 0.24 & 1.68 \\
Sound duration & -0.14 & -0.01 & -0.12 \\
Pulse duration & 12.48 & $10 \cdot 72$ & $10 \cdot 08$ \\
Pulse period & 0.67 & 1.47 & 0.73 \\
Peak frequency & 0.04 & 0.04 & 0.04 \\
\hline
\end{tabular}


TABLE III. Acoustic features measured in knocks, grunts, growls and bursts of sounds. Values are means \pm s.D. and range is given in parentheses

\begin{tabular}{|c|c|c|c|c|}
\hline & Parameters & Knock & Grunt & Growl \\
\hline \multirow[t]{6}{*}{ Sounds } & $n$ & 968 & 693 & 64 \\
\hline & Sound duration (ms) & $\begin{array}{l}11 \cdot 8 \pm 6 \cdot 8 \\
(2 \cdot 6-30 \cdot 8)\end{array}$ & $\begin{array}{l}70 \cdot 1 \pm 24 \cdot 3 \\
(18 \cdot 3-297 \cdot 5)\end{array}$ & $\begin{array}{r}263 \cdot 6 \pm 167 \cdot 3 \\
(50 \cdot 8-846 \cdot 5)\end{array}$ \\
\hline & Pulse duration (ms) & $\begin{array}{l}5 \cdot 6 \pm 0 \cdot 9 \\
(2 \cdot 6-9 \cdot 8)\end{array}$ & $\begin{array}{l}5 \cdot 6 \pm 0 \cdot 8 \\
(3 \cdot 6-8 \cdot 4)\end{array}$ & $\begin{array}{l}4 \cdot 6 \pm 0 \cdot 4 \\
(3 \cdot 9-5 \cdot 5)\end{array}$ \\
\hline & Number of pulses & $\begin{array}{l}1 \cdot 8 \pm 0 \cdot 8 \\
\quad(1-4)\end{array}$ & $\begin{array}{c}6 \cdot 2 \pm 2 \cdot 3 \\
\quad(2-37)\end{array}$ & $\begin{array}{r}41 \cdot 1 \pm 26 \cdot 5 \\
\quad(9-140)\end{array}$ \\
\hline & Pulse period (ms) & $\begin{array}{l}7 \cdot 8 \pm 2 \cdot 3 \\
(3 \cdot 4-19 \cdot 6)\end{array}$ & $\begin{array}{l}11 \cdot 0 \pm 1 \cdot 9 \\
(5 \cdot 7-18 \cdot 6)\end{array}$ & $\begin{array}{l}6 \cdot 2 \pm 0 \cdot 9 \\
(4 \cdot 6-8 \cdot 7)\end{array}$ \\
\hline & Peak frequency $(\mathrm{Hz})$ & $\begin{array}{l}510 \pm 160 \\
(246-1064)\end{array}$ & $\begin{array}{l}478 \pm 202 \\
(229-1170)\end{array}$ & $\begin{array}{l}499 \pm 159 \\
(304-1018)\end{array}$ \\
\hline \multirow[t]{4}{*}{ Bursts of sounds } & $n$ & 130 & 85 & - \\
\hline & Burst duration (s) & $\begin{array}{r}1 \cdot 4 \pm 2 \cdot 1 \\
(<0 \cdot 1-9 \cdot 2)\end{array}$ & $\begin{array}{c}1 \cdot 1 \pm 2 \cdot 0 \\
(<0 \cdot 1-12 \cdot 7)\end{array}$ & - \\
\hline & $\begin{array}{l}\text { Number of sounds } \\
\text { in a burst }\end{array}$ & $\begin{array}{c}5 \cdot 3 \pm 5 \cdot 1 \\
(1-30)\end{array}$ & $\begin{array}{c}4 \cdot 6 \pm 6 \cdot 5 \\
(1-52)\end{array}$ & - \\
\hline & $\begin{array}{l}\text { Interval between } \\
\text { sounds (ms) }\end{array}$ & $\begin{array}{l}324 \cdot 0 \pm 368 \cdot 1 \\
\quad(5 \cdot 6-2172 \cdot 0)\end{array}$ & $\begin{array}{l}253 \cdot 0 \pm 287 \cdot 7 \\
\quad(6 \cdot 4-1858 \cdot 0)\end{array}$ & - \\
\hline
\end{tabular}

patterns. Other triglids, such as the streaked gurnard Trigloporus lastoviza (Bonnaterre) and the American searobins Prionotus spp., are also known to increase the rate of sound production during competitive feeding (Fish, 1954; Amorim \& Hawkins, 2000) but they seem to have a smaller repertoire of agonistic sounds than the grey gurnard. The streaked gurnard emits only one sound type (very long growls) during competitive feeding (Amorim \& Hawkins, 2000), while the northern searobin Prionotus carolinus (L.) and the striped searobin Prionotus evolans (L.) emit at least one sound type, squawks and grunts respectively, when fed alone or competitively (Fish, 1954). The terminology used to label the sounds produced by the searobins is however confusing (Fish, 1954; Moulton, 1956; Fish \& Mowbray, 1970), not permitting a clear identification of the total number of distinct sound types produced by these species.

All sounds emitted by the grey gurnard were made up of repeated, short, low frequency pulses and were readily distinguishable by the human ear, and statistically discriminated by their pulse duration, number of pulses and pulse period. Knocks, grunts and growls differed considerably in their number of pulses and therefore in sound duration. Typical number of pulses for knocks, grunts and growls were 1-2, 4-8 and 10-40 respectively, and average sound durations were 12, 70 and $264 \mathrm{~ms}$, respectively. Average pulse period also differed c. $3 \mathrm{~ms}$ between knocks and grunts and $c .5 \mathrm{~ms}$ between grunts and growls. Sounds, or at least grunts, are generated in this species by synchronous contractions of the left and right sonic muscles, as proven by simultaneous electromyograms and sound recordings registered during spontaneous sound production (Amorim, 1996). This suggests that the basic unit of sound production is a 


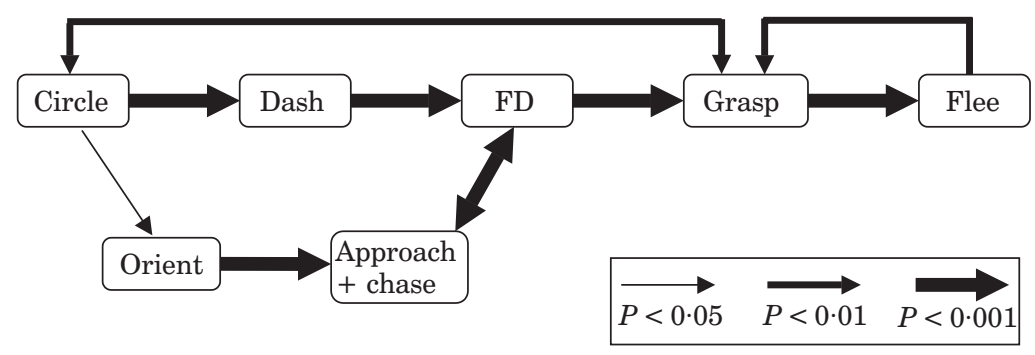

FIG. 4. Behavioural sequences observed during competitive feeding interactions occurring more frequently than expected by chance alone. Sequential dependence of behavioural acts was tested by comparing observed frequencies with those expected if the observations were independent. The probabilities were determined by the programme ACTUS, a simulation analysis for tests of independence of contingency tables $(n=1372)$. FD, frontal display.

single pulse. Some knocks and growls, however, show a double-pulse structure suggesting that perhaps in some occasions the sonic muscles may contract nonsimultaneously as observed in the northern searobin (Bass \& Baker, 1991).

Although knocks, grunts and growls can be discriminated into three different sound types, it is not clear whether hearing generalists such as the grey gurnard, are able to discriminate sounds with such differences in the temporal characteristics of sounds (Fay \& Simmons, 1999; Wysocki \& Ladich, 2003). The plainfin midshipman Porichthys notatus Girard, seems capable of fine temporal resolution (Bodnar \& Bass, 1997; McKibben \& Bass, 2001), and the pumpkinseed, Lepomis gibbosus (L.) seems to be able to process the pulses of conspecifics sounds, each contributing to a compound brainwave recorded at the brainstem (Wysocki \& Ladich, 2003). In general, the temporal patterning of sounds is believed to be the most important feature in acoustic communication by fishes (Winn, 1964; Myrberg et al., 1978). Amorim (1996) has performed behavioural playback tests to ascertain whether grey gurnards can differentiate between knocks, grunts and growls, but the experiments elicited no responses. Playback experiments with teleosts often fail to elicit a response unless the sounds are accompanied by visual stimuli (Hawkins \& Myrberg, 1983; Ladich, 1997).

Knocks and grunts emitted by the grey gurnard are likely to differ in their biological significance since knocks were mainly associated with grasping food and other non-agonistic behaviour, while grunts were mainly associated with frontal displays. Growls were emitted typically at the end of a grunt sequence. The main difference between grunts and growls is the higher pulse number and repetition rate. These features are thought to increase as the fish's motivational state becomes more intense (Myrberg et al., 1978; Hawkins \& Amorim, 2000). As the presence of a fish grasping food usually made competitors circle or dash, however, the emission of knocks, grunts and growls could perhaps be seen as a continuum in aggressive motivation.

The sequences of behavioural acts observed during feeding interactions suggest that grey gurnards used both scramble and contest competition tactics (Milinsky \& Parker, 1991), as foraging fish succeeded in grasping a piece of food either by being the fastest to snap a food item and by circling the feeding area until they had an opportunity to grasp without being aggressive, or by 

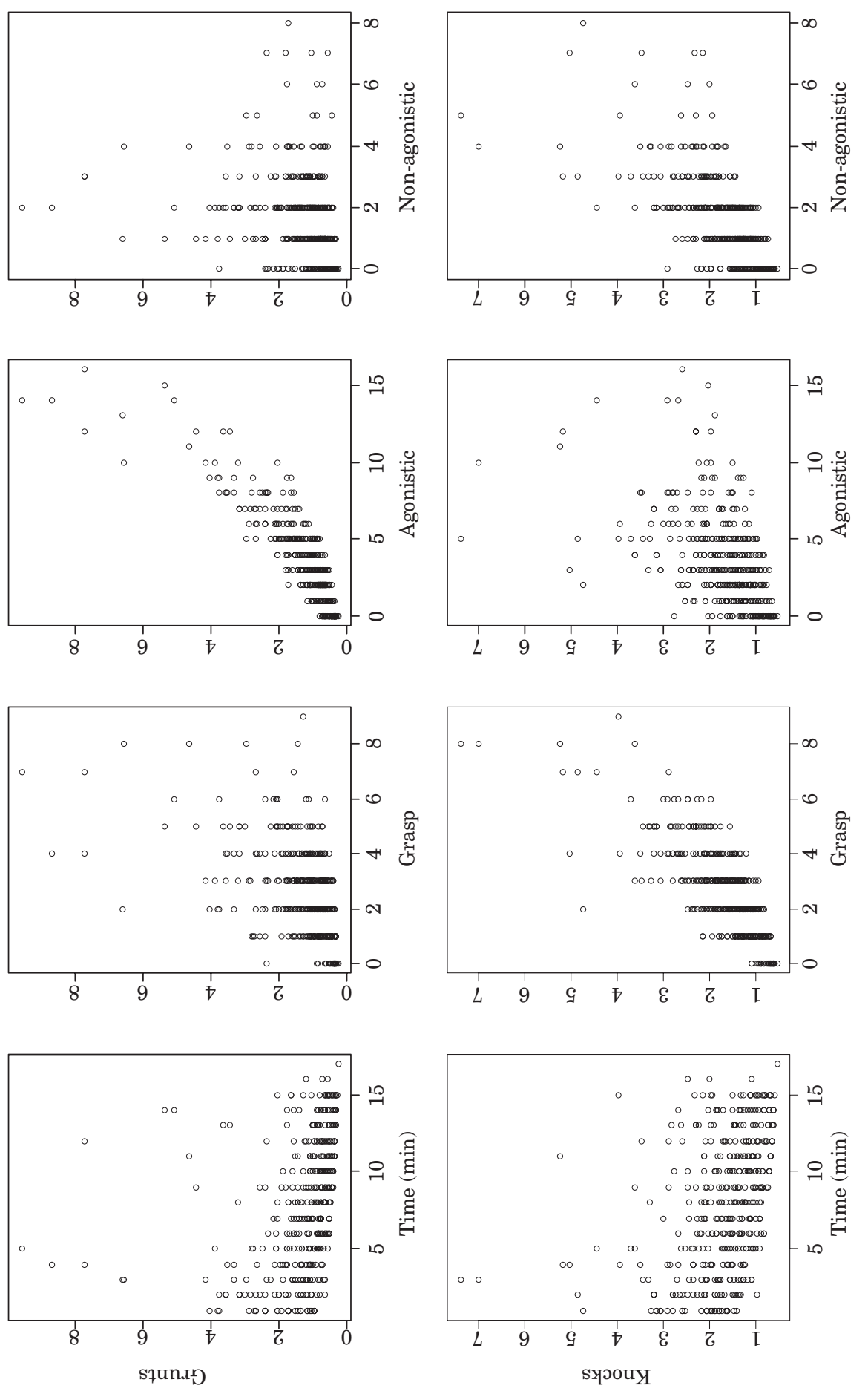
TABle IV. Results of GLM with Poisson distribution fitted to the number of grunt and knock bursts produced per minute in relation to time and the associated behaviours

\begin{tabular}{llrrrr}
\hline Sound & Variable & Parameter & S.E. & \multicolumn{1}{c}{$t$-value } & \multicolumn{1}{c}{$P$} \\
\hline \multirow{2}{*}{ Grunt } & Time & -0.064 & 0.010 & -6.18 & $<0.001$ \\
& Grasp & 0.055 & 0.028 & 1.98 & 0.048 \\
& Agonistic & 0.171 & 0.013 & 13.26 & $<0.001$ \\
& Non-agonistic & 0.059 & 0.033 & 1.78 & 0.076 \\
Knock & Time & -0.039 & 0.010 & -3.75 & $<0.001$ \\
& Grasp & 0.154 & 0.028 & 5.47 & $<0.001$ \\
& Agonistic & 0.020 & 0.016 & 1.24 & 0.216 \\
& Non-agonistic & 0.152 & 0.029 & 5.23 & $<0.001$ \\
\hline
\end{tabular}

performing agonistic behaviour such as approaches and frontal displays. The emission of sounds may confer advantages to a foraging fish. Knock production associated with grasp, circle and dash, may reflect a state of feeding arousal caused by the sight of food, although it could also serve as a warning to potential competitors. Grunts were mainly emitted during frontal displays suggesting that they are aggressive signals. The spread-out of fins in a frontal display, in particular of the large pectorals, may be enhanced by grunting, and seemed an effective behaviour in deterring other fish from getting closer to the sound emitter and the food items, as this was the behaviour that most frequently preceded grasps.

The role of sound production in feeding interactions has been rarely mentioned in the literature but is probably widespread. Sound production outside the reproductive season by croakers (Sciaenidae), longspine squirrelfish Holocentrus rufus (Walbaum), gurnards (Triglidae) and haddock Melanogrammus aeglefinus (L.) has been related to feeding activity (Fish, 1954; Moulton, 1958; Protasov, 1965; Hawkins, 1993; Amorim \& Hawkins, 2000). The present work provides one of the few detailed studies on the use of acoustic emissions during competitive feeding in fishes (Amorim \& Hawkins, 2000), demonstrating the significance of acoustical signals in non-territorial fish species. Although the association of knocks and grunts with particular behavioural displays is not sufficient to validate their function, it is an easy and a non-intrusive method that gives valuable cues of the role of different sound types emitted by fishes (Torricelli et al., 1986; Amorim \& Hawkins, 2000; Amorim et al., 2003). Given that the social significance of sound emissions is unknown in many fish species because experimental studies demonstrating the function of fish sounds are difficult to achieve or intrusive (Bass \& McKibben, 2003; Ladich, 2003), it is suggested that this method could be more widely applied in fish sound production studies.

This study was partially supported by a grant (BD/2346/92-IG, Programa Ciência) and by the pluriannual programme (UI\&D 331/94) of FCT. The authors are thankful to D. Urquhart and M. Burns for their technical support, to V. Almada for valuable suggestions for the behavioural analysis and to M. Fine for comments on the manuscript. 


\section{References}

Amorim, M. C. P. (1996). Acoustic communication in triglids and other fishes. Ph.D. Thesis, University of Aberdeen.

Amorim, M. C. P. \& Hawkins, A. D. (2000). Growling for food: acoustic emissions during competitive feeding of the streaked gurnard. Journal of Fish Biology 57, 895-907. doi: 10.1006/jfbi.2000.1356.

Amorim, M. C. P., Fonseca, P. J. \& Almada, V. C. (2003). Sound production during courtship and spawning of the cichlid Oreochromis mossambicus: male-female and male-male interactions. Journal of Fish Biology 62, 658-672. doi: 10.1046/j.00221112.2003.00054.x.

Bass, A. H. \& Baker, R. (1991). Evolution of homologous vocal control traits. Brain, Behavior and Evolution 38, 240-254.

Bass, A. H. \& McKibben, J. R. (2003). Neural mechanisms and behaviors for acoustic communication in teleost fish. Progress in Neurobiology 69, 1-26.

Bodnar, D. A. \& Bass, A. H. (1997). Temporal coding of concurrent acoustic signals in auditory midbrain. The Journal of Neuroscience 17, 7553-7564.

Estabrook, C. B. \& Estabrook, G. F. (1989). A solution to the problem of small samples in the analysis of two-way contingency tables. Historical Methods 22, 5-8.

Fay, R. R. \& Simmons, A. M. (1999). The sense of hearing in fishes and amphibians. In Comparative Hearing: Fish and Amphibians (Fay, R. R. \& Popper, A. N., eds), pp. 269-318. New York: Springer.

Fish, J. F. (1954). The character and significance of sound production among fishes of the Western North Atlantic. Bulletin of the Bingham Oceanographic Collection 14, $1-109$.

Fish, J. F. \& Mowbray, W. H. (1970). Sounds of Western North Atlantic Fishes. Baltimore, MD: John Hopkins Press.

Grant, J. W. A. (1993). Whether or not to defend? The influence of resource distribution. Marine Behaviour and Physiology 23, 137-153.

Goldberg, J. L., Grant, J. W. A. \& Lefebvre, L. (2001). Effects of temporal predictability and spatial clumping of food on the intensity of competitive aggression in the Zenaida dove. Behavioral Ecology 12, 490-495.

Hawkins, A. D. (1993). Underwater sound and fish behaviour. In Behaviour of Teleost Fishes (Pitcher, T. J., ed.), pp. 129-169. London: Chapman \& Hall.

Hawkins, A. D. \& Amorim, M. C. P. (2000). Spawning sounds of the male haddock, Melanogrammus aeglefinus. Environmental Biology of Fishes 59, 29-41.

Hawkins, A. D. \& Myrberg, A. A., Jr. (1983). Hearing and sound communication underwater. In Bioacoustics. A Comparative Approach (Lewis, B., ed.), pp. 347-405. London: Academic Press.

Huntingford, F. \& Turner, A. (1987). Animal Conflict. London: Chapman \& Hall.

Ladich, F. (1997). Agonistic behaviour and significance of sounds in vocalizing fish. Marine and Freshwater Behavior and Physiology 29, 87-108.

Ladich, F. (2003). Sound production and acoustic communication. In The Senses of Fishes (von der Emde, G., Mogdans, J. \& Kapoor, B. G., eds), pp. 210-230. New Delhi: Narosa Publishing House.

Ladich, F., Brittinger, W. \& Kratochvil, H. (1992). Significance of agonistic vocalization in the croaking gourami (Trichopsis vittatus, Teleostei). Ethology 90, 307-314.

Martin, P. \& Bateson, P. (1993). Measuring Behaviour. An Introductory Guide, 2nd edn. Cambridge: Cambridge University Press.

McCulough, P. \& Nelder, J. A (1989). Generalised Linear Models, 2nd edn. London: Chapman \& Hall.

McKibben, J. R. \& Bass, A. H. (2001). Effects of temporal envelope modulation on acoustic signal recognition in a vocal fish, the plainfin midshipman. The Journal of the Acoustical Society of America 109, 2934-2943.

Milinsky, M. \& Parker, G. A. (1991). Competition for resources. In Behavioural Ecology. An Evolutionary Approach, 3rd edn (Krebs, J. R. \& Davies, N. B., eds), pp. 137-168. Oxford: Blackwell. 
Moulton, J. M. (1956). Influencing the calling of sea robins (Prionotus spp.) with sound. Biological Bulletin 111, 393-398.

Moulton, J. M. (1958). A summer silence of sea robins. Copeia 1958, 234-235.

Moulton, J. M. (1963). Acoustic behaviour of fishes. In Acoustic Behaviour of Animals (Busnel, R. G., ed.), pp. 655-693. Amsterdam: Elsevier.

Myrberg, A. A., Jr. (1997). Sound production by a coral reef fish (Pomacentrus partitus): Evidence for a vocal, territorial "keep-out" signal. Bulletin of Marine Science 60, $1017-1025$.

Myrberg, A. A., Jr., Spanier, E. \& Ha, S. J. (1978). Temporal patterning in acoustical communication. In Contrasts in Behaviour (Reese, E. S. \& Lighter, F. J., eds), pp. 137-179. New York: John Wiley.

Papaconstantinou, C. (1983). Observations on the ecology of gurnards (Pisces, Triglidae) of the Greek seas. Cybium 7, 71-88.

Protasov, V. R. (1965). Bioakustka Ryb. Moscow: Akademia. Nauk, S.S.S.R.

Rigley, L. \& Muir, J. (1979). The role of sound production in the brown bullhead Ictulurus nebulosus. Proceedings of the Pennsylvania Academy of Sciences 53, $132-134$.

Robb, S. E. \& Grant, J. W. A. (1998). Interactions between the spatial and temporal clumping of food affect the intensity of aggression in Japanese medaka. Animal Behaviour 56, 29-34.

Schwarz, A. (1974). The inhibition of aggressive behaviour by sound in the cichlid fish, Cichlasoma centrarchus. Zeitschrift für Tierpsychologie 35, 508-517.

Torricelli, P., Lugli, M. \& Gandolfi, G. (1986). A quantitative analysis of the occurrence of visual and acoustic displays during courtship in the freshwater goby, Padogobius martensi (Gunther, 1961) (Pisces, Gobiidae). Bollettino di Zoologia 53, 85-89.

Valinski, W. \& Rigley, L. (1981). Function of sound production by the shunk loach Botia horae (Pisces, Cobitidae). Zeitschrift für Tierpsychologie 55, 161-172.

Venables, W. N. \& Ripley, B. D. (2002). Modern Applied Statistics with S, 4th edn. New York : Springer.

Wheeler, A. (1969). The Fishes of the British Isles and North-West Europe. East Lansing, MI: Michigan State University Press.

Winn, H. E. (1964). The biological significance of fish sounds. In Marine Bio-acoustics (Tavolga, W. N., ed.), pp. 213-230. Oxford: Pergamon Press.

Wysocki, L. E. \& Ladich, F. (2003). The representation of conspecifics sounds in the auditory brainstem of teleost fishes. The Journal of Experimental Biology 206, 2229-2240. 